\title{
2003-04 ACRL chapter conferences/events
}

\begin{tabular}{|c|c|c|c|}
\hline Chapter & Date & Description of Event & Location \\
\hline Alabama & Apr. 20-23, 2004 & AACRL Annual Meeting & Montgomery \\
\hline California & Apr. 22-25, 2004 & CARL Annual Conference & Pasadena \\
\hline $\begin{array}{c}\text { Delaware } \\
\text { Valley }\end{array}$ & Oct. 24, 2003 & 2003 Fall Program & Bryn Mawr, PA \\
\hline Florida & Mar. $22-24,2004$ & $\begin{array}{l}\text { FLA Annual Conference and Exhibition: } \\
\text { "Vibrant Voices, Vital Libraries" }\end{array}$ & Daytona Beach \\
\hline & Oct. 17,2003 & FLA Workshop: "Professional Pizzazz" & Orlando \\
\hline Georgia & Oct. $22-24,2003$ & $\begin{array}{l}\text { Georgia Council of Media Organizations } 2003 \\
\text { Conference: "Cooperative Ventures XV: } \\
\text { Connecting, Leaming, Changing Lives" }\end{array}$ & Jekyll Island \\
\hline Illinois & $\begin{array}{l}\text { Mar. 31-Apr. 2, } \\
2004\end{array}$ & $\begin{array}{l}\text { IACRL Spring Conference: "Redefining } \\
\text { Ourselves: Academic Librarianship at } \\
\text { the Ctossroads" }\end{array}$ & Oak Brook \\
\hline Indiana & Apr. 12-14, 2004 & 2004 Annual Conference & Indianapolis \\
\hline Iowa & Apr. 16,2004 & ILA/ACRL Spring Conference & Pella \\
\hline Kansas & Oct. $23-24,2003$ & Cuts Fall Conference & Wichita \\
\hline Kentucky & Apr. 14-16, 2004 & KLA and SLA Joint Spring Conference & $\begin{array}{l}\text { Barren River } \\
\text { State Resort } \\
\text { Park }\end{array}$ \\
\hline Louisiana & Nov. $6-7,2003$ & $\begin{array}{l}\text { ACRL Louisiana } 2003 \text { Conference: "Librarians } \\
\text { as Leaders for Learning: Information Literacy } \\
\text { in Today's World" }\end{array}$ & $\begin{array}{l}\text { Toledo Bend } \\
\text { Lake }\end{array}$ \\
\hline Michigan & Oct. $29-31,2003$ & MLA Annual Conference & Lansing \\
\hline Minnesota & Sept. 24-26, 2003 & $\begin{array}{l}2003 \text { Annual Conference: "One Conference, } \\
\text { One Book" }\end{array}$ & Rochester \\
\hline Missouri & Oct. $1-3,2003$ & MLA 2004 Annual Conference & Springfield \\
\hline Montana & Apr. 24-27, 2004 & $\begin{array}{l}\text { MiA Annual Conference: "It's a Matter of } \\
\text { Speech" }\end{array}$ & Bozeman \\
\hline Nebraska & Oct. $29-30,2003$ & NLA/NEMA Annual Conference & Omaha \\
\hline
\end{tabular}




\section{3-04 ACRL c̊hapter conferences/events}

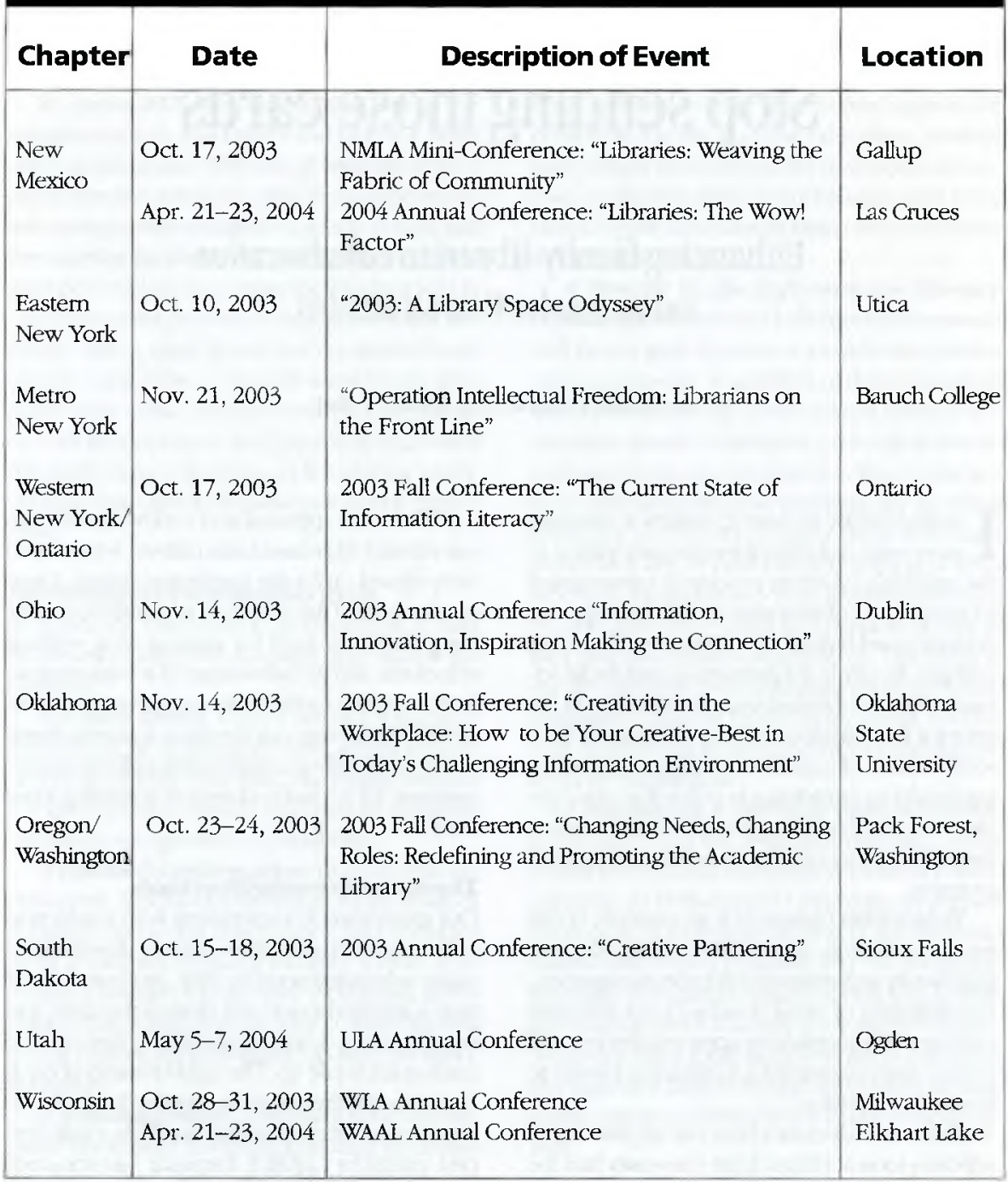

\section{("Diversity" continued from page 595)}

McLeod, P. L., Lobel, S. A., and Cox, T. H. Jr. "Ethnic Diversity and Creativity In Small Groups." Small Group Research (1996) 27: 246-64.

Norlin, Elaina. "University Goes Back to Basics to Reach Minority Students." American Libraries (August 2001): 60-62.

Richard, Orlando. "Racial Diversity, Business Strategy, and Firm Performance: A ResourceBased View." Academy of Management Joumal 43 (2): 164-77.
Wilder, Stanley. "The Demographics of Li brary Leadership." Human Resource Management Symposium 2002. www.arl.org/training/institutes/ hrppt/wilder.htm.

\section{Notes}

1. See www.ala.org/spectrum.

2. P. L. McLeod, S. A. Lobel, and T. H. Cox Jr., "Ethnic Diversity and Creativity In Small Groups," Small Group Researcb (1996) 27: 246-64. 